\title{
Erratum to: Interactional Order and Constructed Ways of Seeing with Touchless Imaging Systems in Surgery
}

Kenton O’Hara ${ }^{1}$, Gerardo Gonzalez ${ }^{2}$, Graeme Penney ${ }^{2}$, Abigail Sellen ${ }^{1}$, Robert Corish ${ }^{1}$, Helena Mentis ${ }^{4}$, Andreas Varnavas ${ }^{2}$, Antonio Criminisi ${ }^{1}$, Mark Rouncefield ${ }^{3}$, Neville Dastur ${ }^{2} \&$ Tom Carrell ${ }^{2}$

${ }^{1}$ Microsoft Research, Cambridge, UK (E-mail: oharakenton@gmail.com); ${ }^{2}$ Kings College London, London, UK; ${ }^{3}$ Lancaster University, Lancaster, UK; ${ }^{4}$ University of Maryland, Baltimore County, USA

\section{Erratum to: Comput Supported Coop Work (2014) DOI 10.1007/s10606-014-9203-4}

The affiliation for co-author Helena Mentis was published incorrectly in the original article. The correct affiliation is University of Maryland, Baltimore County, USA. 